Mettler, Dispositional Mindfulness and Adjustment to University, 'Journal of College Student Retention: Research, Theory \& Practice' $(21,1)$ pp. 38-52. Copyright (C) 2017. DOI:

$10.1177 / 1521025116688905$. Users who receive access to an article through a repository are reminded that the article is protected by copyright and reuse is restricted to non-commercial and no derivative uses. Users may also download and save a local copy of an article accessed in an institutional repository for the user's personal reference. For permission to reuse an article, please follow our Process for Requesting Permission.

\title{
Dispositional Mindfulness and Adjustment to University
}

\author{
Abstract \\ The transition to university is a stressful period for young adults; however, there has been \\ limited research examining the predictive role of dispositional mindfulness in supporting first- \\ year students' adjustment to university. The current study sought to examine the relative \\ contribution of gender, self-efficacy, perceived social support from friends and family, and \\ dispositional mindfulness to domains of university adjustment (academic, social, personal or \\ emotional, and institutional attachment). The sample consisted of 101 first-year university \\ students $(73 \%$ female; $M=18.20$ years, $S D=0.79)$ and all data were collected using an online \\ survey. Findings revealed dispositional mindfulness significantly predicted university adjustment \\ even when controlling for self-efficacy and perceived social support. The present study is the \\ first to provide empirical support for the protective role of dispositional mindfulness in \\ university adjustment.
}

\section{Keywords}

mindfulness, university adjustment, young adulthood

\section{Introduction}

The transition to university is a very stressful developmental period for students and is associated with a number of academic, personal, social, and emotional difficulties (Brandy, Penckofer, Solari-Twadell, \& Velsor-Friedrich, 2015; Crede' \& Niehorster, 2012; Tao, Dong, Pratt, Hunsberger, \& Pancer, 2000). In fact, up to 53.5\% of undergraduate students indicated having experienced above average stress levels over the past year (American College Health Association, 2015). Contributors to this stress include greater academic demands, separation 
from family and friends, new living arrangements, unfamiliar social settings, new responsibilities, financial strain, and lack of former academic preparation (Adams, Meyers, \& Beidas, 2016; Crede'\& Niehorster, 2012; Dyson \& Renk, 2006; Friedlander, Reid, Shupak, \& Cribbie, 2007; Martinez, Sher, Krull, \& Wood, 2009; Ramler, Tennison, Lynch, \& Murphy, 2016). Struggling with stress impacts students' overall adjustment (Friedlander et al., 2007) which can in turn affect academic performance and retention (Ramler et al., 2016). Considering the importance of school adjustment, it is important to identify potential protective factors that facilitate students' adjustment following their transition to university.

Mindfulness has been suggested as a potential protective factor for the stress experienced by university students (e.g., Bamber \& Schneider, 2016; Bergin \& Pakenham, 2016; Feldman, Lavallee, Gildawie, \& Greeson, 2016; Palmer \& Rodger, 2009), and recently, a mindfulnessbased stress reduction intervention has been shown to be effective in contributing to improved first-year university adjustment (Ramler et al., 2016). Mindfulness consists of paying attention in the present moment, purposefully, and with acceptance (Kabat-Zinn, 1994). It has been characterized both as a state, whereby individuals experience moment-by- moment mindfulness, or as a disposition, which taps into individuals' general tendency to be mindful (e.g., Brown \& Ryan, 2003). Additionally, mindfulness- based interventions have been shown to increase both state and dispositional mindfulness, and gains are maintained over time (Khoury et al., 2013; Shapiro, Brown, Thoresen, \& Plante, 2011).

Research has demonstrated that dispositional mindfulness is associated with greater wellbeing and more adaptive functioning. For example, higher dispositional mindfulness has been associated with lower anxiety, depression, emotional reactivity, and rumination, as well as enhanced ability to cope with stressful or distressing situations and greater subjective well-being 
Mettler, Dispositional Mindfulness and Adjustment to University, 'Journal of College Student Retention: Research, Theory \& Practice' $(21,1)$ pp. 38-52. Copyright (C) 2017. DOI:

$10.1177 / 1521025116688905$. Users who receive access to an article through a repository are reminded that the article is protected by copyright and reuse is restricted to non-commercial and no derivative uses. Users may also download and save a local copy of an article accessed in an institutional repository for the user's personal reference. For permission to reuse an article, please follow our Process for Requesting Permission.

(Bergomi, Stro“hle, Michalak, Funke, \& Berking, 2013; Feldman et al., 2016; Hanley,

Warner, \& Garland, 2015; Kadziolka, Di Pierdomenico, \& Miller, 2016; Keng, Smoski, \&

Robins, 2016).

Moreover, although dispositional mindfulness has not been examined as a potential protective factor for adjustment to university, it has been positively associated with individual factors such as self-efficacy and perceived social support, which have been found to contribute to university adjustment. In particular, higher dispositional mindfulness has been found to be associated with greater self-efficacy (Caldwell, Harrison, Adams, Quin, \& Greeson, 2010; Klainin-Yobas et al., 2016). Additionally, self-efficacy has been associated with students' academic, social, and emotional adjustment (Chemers, Hu, \& Garcia, 2001; Friedlander et al., 2007; Krumrei-Mancuso, Newton, Kim, \& Wilcox, 2013; Ramos-Sanchez \& Nichols, 2007). Furthermore, levels of self-efficacy at the beginning of the year have been found to predict better adjustment to university later on in the year (Ramos-Sanchez \& Nichols, 2007).

In addition, perceived social support has been found to be a protective factor contributing to university adjustment (Chao, 2012; Lee, Dickson, Conley, \& Holmbeck, 2014). In a study examining social support in first-year university students, social support was found to be stable over the course of a semester; however, perceived social support from parents and friends increased while that from siblings and teachers decreased (Tao et al., 2000). Furthermore, Friedlander et al. (2007) found that, unlike perceived social support from family, perceived social support from friends predicted improved adjustment in first-year university students. Considering that mindfulness has been shown to promote both intrapersonal and interpersonal awareness (Parker, Nelson, Epel, \& Siegel, 2015), it is possible that mindfulness could influence perceived social support. 
Therefore, it may be important to use mindfulness in interventions aimed at fostering university adjustment; however, it is necessary to better understand the role of dispositional mindfulness in university adjustment when taking into account self-efficacy and perceived social support. Furthermore, although the literature provides preliminary support for the role of mindfulness, self- efficacy, and social support on adjustment to university, it remains unclear whether these effects differ according to students' gender (e.g., Chemers et al., 2001; Friedlander et al., 2007; Marks, Sobanski, \& Hine, 2010; Ramos- Sanchez \& Nichols, 2007; Tao et al., 2000; Tinsley Li, Berman Albert, \& Dwelle, 2014).

Thus, the objectives of the present study were to (a) explore the relations between dispositional mindfulness, gender, self-efficacy, perceived social support from friends and family, and domains of adjustment to university (academic, social, personal or emotional, and institutional attachment); and (b) examine the contribution of dispositional mindfulness to different aspects of adjustment to university while controlling for gender, self-efficacy, and perceived social support from friends and family. Specifically, it is hypothesized that there will be positive associations between dispositional mindfulness, self-efficacy, perceived social support, and domains of adjustment to university (H1). It is also hypothesized that dispositional mindfulness will significantly predict adjustment to university even when controlling for selfefficacy and perceived social support (H2). No specific hypotheses were made regarding gender differences as these were exploratory in nature.

\section{Methods}

\section{Participants}

Participants $(n=92 ; 71.7 \%$ female; $M$ years $=18.2$ years, $S D$ years $=0.76)$ were a sample of first-year university students recruited in February 2016 from a large urban English- 
Mettler, Dispositional Mindfulness and Adjustment to University, 'Journal of College Student Retention: Research, Theory \& Practice' $(21,1)$ pp. 38-52. Copyright (C) 2017. DOI:

$10.1177 / 1521025116688905$. Users who receive access to an article through a repository are reminded that the article is protected by copyright and reuse is restricted to non-commercial and no derivative uses. Users may also download and save a local copy of an article accessed in an institutional repository for the user's personal reference. For permission to reuse an article, please follow our Process for Requesting Permission.

language university in Quebec, Canada. The majority of students reported a program of study in the Faculty of Science (38.5\%), followed by Arts (38.5\%), Engineering (12.1\%), Management (4\%), and Music (2.2\%). Participants predominantly identified themselves as Caucasian (69.2\%), with others reporting Asian (16.5\%), South Asian (3.3\%), and other (7.7\%) ethnicities.

\section{Measures}

Mindfulness. The Mindful Attention Awareness Scale (MAAS; Brown \& Ryan, 2003) is a selfreport unidimensional measure of dispositional mindfulness that has been validated in university students. The MAAS comprises 15 items that focus on the lack of mindful attention and awareness (e.g., 'II find it difficult to stay focused on what's happening in the present') rated on a 6-point Likert scale (1 almost always to 6 almost never). Higher scores on the MAAS reflect dispositional mindfulness or absence of inattention. In the present study, the internal consistency was high $(\alpha=.88)$.

General self-efficacy. The General Self-Efficacy scale (GSE; Schwarzer \& Jerusalem, 1995) is a widely used self-report measure of self-efficacy beliefs. It consists of 10 items associated with positive coping in a number of situations (e.g., "I can usually handle whatever comes my way') rated on a 4-point Likert scale (1 not at all true to 4 exactly true). The GSE had good internal consistency in the present study, with a Cronbach's alpha of .85.

Perceived social support. The Multidimensional Scale of Perceived Social Support (MSPSS; Zimet, Dahlem, Zimet, \& Farley, 1988) is a self-report measure of individuals' perceived social support from family, friends, and significant others. It consists of three subscales with a total of 12 items (e.g., "I get the emotional help and support I need from my family" and "I can talk about my problems with my friends'") rated on a 7-point Likert scale (1 very strongly disagree to 7 very strongly agree). For the purpose of this study, only the perceived social support from 
family and friends subscales were used and each had good internal consistency (support from family: $\alpha=.89$; support from friends: $\alpha=.91$ ).

Adjustment to university. The Student Adaptation to College Questionnaire (SACQ; Baker \& Siryk, 1999) is used to assess students' adjustment to university. It consists of 67 items and four subscales related to specific domains of adjustment: (a) academic (23 items; participants' ability to cope with the university's educational demands), (b) social (18 items; participants' interpersonal and social experiences at university), (c) personal or emotional (15 items; participants' psychological and physical well-being at university), and (d) institutional attachment (14 items; participants' general satisfaction with the university in which they are enrolled). Items include the following statements: "“'I’ve been keeping up to date on my academic work" (academic), "I am very involved with social activities in college", (social), "Lately I have been feeling blue and moody a lot'” (personal), and "Lately, I have been giving a lot of thought to transferring to another college', (institutional attachment). Participants rate whether these statements apply to them on a 9-point Likert scale (1 applies very closely to me to 9 doesn't apply to me at all), with higher scores indicating better adjustment to university. Each subscale of the SACQ had good internal consistency in the present study (academic: $\alpha=.85$; social: $\alpha=.88$; personal or emotional: $\alpha=.85$; institutional attachment: $\alpha=.86$ ).

\section{Procedure}

Participants from an existing database were emailed an invitation to participate in this study. Those who indicated they were interested in participating were then sent an individualized link and password to complete an online survey. This survey consisted of a number of confidential questionnaires, including the MAAS, GSE, MSPSS, and SACQ, as well as a consent form. Following completion of the online survey, students received an e-mail with debriefing 
Mettler, Dispositional Mindfulness and Adjustment to University, 'Journal of College Student Retention: Research, Theory \& Practice' $(21,1)$ pp. 38-52. Copyright (C) 2017. DOI:

$10.1177 / 1521025116688905$. Users who receive access to an article through a repository are reminded that the article is protected by copyright and reuse is restricted to non-commercial and no derivative uses. Users may also download and save a local copy of an article accessed in an institutional repository for the user's personal reference. For permission to reuse an article, please follow our Process for Requesting Permission.

information, a list of resources, and information about research compensation. Participants were entered in a raffle for one of twenty $25 \$$ cash prizes. This study was approved by the university's institutional ethics review board.

\section{Data Analysis}

Pearson and point-biserial correlation coefficients corrected using the Bonferroni method were used to assess the associations between dispositional mindfulness, gender, self-efficacy, perceived social support from friends and family, and different aspects of adjustment to university (H1). To test $\mathrm{H} 2$, hierarchical multiple regression analyses were then performed to predict the contribution of dispositional mindfulness when controlling for self-efficacy and perceived social support from friends and family for each of the four domains of adjustment to university (academic, social, personal or emotional, and institutional attachment). The predictor variables were selected based on the significance of the correlation coefficients.

\section{Results}

All data were analyzed using SPSS version 23. More than $5 \%$ of the data were found to be missing within each variable except for the perceived social support from friends and family subscales; therefore, Little's Test was performed and revealed that the omitted values were missing completely at random, $\chi^{2}(18) 17.26, p=.506$. Although no multivariate outliers were found, one univariate outlier was identified and excluded from subsequent analyses. The first objective was to explore the associations between dispositional mindfulness, gender, selfefficacy, perceived social support from friends and family, and different aspects of adjustment to university. Table 1 presents a correlation matrix for all of the variables. Given the large number of comparisons, a Bonferroni-corrected alpha was used to test for significance (i.e., .05/= 21 .002). Results revealed no significant point-biserial correlations between gender and any of the 
other predictors or outcome variables. Additionally, contrary to H1, dispositional mindfulness was the only variable significantly correlated with all domains of adjustment to university (academic, social, personal or emotional, and institutional attachment) as well as with selfefficacy and perceived support from family and friends.

The second objective was to examine the contribution of dispositional mindfulness to different domains of adjustment to university when controlling for gender, self-efficacy, and perceived social support from friends and family. Hierarchical multiple regressions were performed for each of the four domains of adjustment to university. Table 2 presents the means and standard deviations for each predictor and outcome variable.

Since gender was not significantly correlated with any of the outcome variables, the second hypothesis was modified and gender was not included as a predictor in any of the regression analyses. Self-efficacy and perceived social support from family and friends were entered in Block 1 of the analyses; dispositional mindfulness was subsequently added to Block 2 of each model. Table 3 presents the results for each regression analysis.

The first hierarchical regression for academic adjustment demonstrated that adding dispositional mindfulness to the model explains $6.4 \%$ additional variance, $F(1,82) 7.04, p .01$, for a total of $25.1 \%, F(4,82)^{1} \frac{6}{6} .88, p<.001$. Specifidally, dispositional mindfulness $(\beta=0.29, p$ $.01)$ and self-efficacy $(\beta=0.23, p .03)$ emerged as significant positive predictors of academic adjustment.

The second hierarchical regression for social adjustment revealed that dispositional mindfulness explained $6.6 \%$ additional variance, $F(1,82)=9.4, p=.003$, for a total of $42.2 \%$, $F(4,82)=14.99, p<.001$. Once again, dispositional mindfulness $(\beta=0.3, p=.003)$ emerged as a significant positive predictor of social adjustment; however, perceived social support from 
Mettler, Dispositional Mindfulness and Adjustment to University, 'Journal of College Student Retention: Research, Theory \& Practice' $(21,1)$ pp. 38-52. Copyright (C) 2017. DOI:

$10.1177 / 1521025116688905$. Users who receive access to an article through a repository are reminded that the article is protected by copyright and reuse is restricted to non-commercial and no derivative uses. Users may also download and save a local copy of an article accessed in an institutional repository for the user's personal reference. For permission to reuse an article, please follow our Process for Requesting Permission.

friends $(\beta=0.41, p<.001)$ also emerged as a significant predictor. Although self-efficacy $(\beta=$

$0.25, p=.007)$ was a significant positive predictor in Block 1 , it was no longer significant $(\beta=$

$.17, p$.062) once dispositional mindfulness was added to the model. The third hierarchical regression for personal and emotional adjustment to university revealed that dispositional mindfulness explained $18.9 \%$ additional variance, $F(1,82) 27.14, p<.001$, for a total of $42.8 \%, F(4,82) 15.32, p<.001$. Similar to the previous regression analyses, dispositional mindfulness $(\beta=0.51, p<.001)$ significantly predicted personal and emotional adjustment. Selfefficacy $(\beta=.31, p=.002)$ and perceived social support from friends $(\beta=0.22, p=.011)$ also emerged as significant positive predictors in Block 1, but were no longer significant in Block 2 when dispositional mindfulness was added to the model.

The fourth hierarchical regression for institutional attachment demonstrated that when dispositional mindfulness was added to the model, an additional $9.3 \%$ of the variance in attachment adjustment scores was explained, $F(1,82)=11.13, p=.001$, for a total of $28.5 \%$, $F(4,82)=9.58, p<.001$. Dispositional mindfulness $(\beta=.35, p=.001)$ and perceived social support from friends $(\beta=.32, p=.002)$ emerged as significant positive predictors of institutional attachment. As hypothesized $(\mathrm{H} 2)$, dispositional mindfulness emerged as a significant predictor of each domain of adjustment to university even when controlling for selfefficacy and perceived social support from friends and family.

\section{Discussion}

The present study sought to (a) examine the associations between dispositional mindfulness, gender, self-efficacy, perceived social support from friends and family, and domains of adjustment to university (academic, social, personal or emotional, and institutional attachment); and (b) assess whether dispositional mindfulness specifically contributed to 
university adjustment when controlling for self-efficacy and perceived social support from friends and family. Consistent with our first hypothesis, dispositional mindfulness was significantly and positively associated with self-efficacy, perceived social support from friends and family, and each domain of adjustment to university. Unexpectedly, beyond being correlated with mindfulness, self-efficacy and perceived social support from friends and family were not all significantly correlated with one another as well as with all domains of adjustment. Supporting our second hypothesis, the findings revealed dispositional mindfulness significantly predicted each domain of adjustment to university even when controlling for self-efficacy and perceived social support from family and friends. With regard to the exploration of gender differences, no significant associations were found. A number of possible explanations might account for these findings.

The lack of gender differences is not surprising given the mixed findings reported in the literature. Although some studies have reported gender differences in dispositional mindfulness (Marks et al., 2010), most studies have not reported any differences (e.g., Palmer \& Rodger, 2009). Furthermore, adjustment to university is a second area of research with mixed findings on gender (Baker \& Siryk, 1999). Since the sample in this study was predominantly female, these results should be interpreted with caution. Future research would benefit from a more careful examination of gender as it pertains to dispositional mindfulness and adjustment to university. Interestingly, dispositional mindfulness was associated with all domains of adjustment to university, as well as with self-efficacy and perceived social sup- port from family and friends. Mindfulness, through living in the present moment and being accepting and nonjudgmental of experience, has been associated with decreased maladaptive coping styles, and increased ability to recover when faced with negative emotions (Keng et al., 2016; Kadziolka, Di Pierdomenico, 
Mettler, Dispositional Mindfulness and Adjustment to University, 'Journal of College Student Retention: Research, Theory \& Practice' $(21,1)$ pp. 38-52. Copyright (C) 2017. DOI:

$10.1177 / 1521025116688905$. Users who receive access to an article through a repository are reminded that the article is protected by copyright and reuse is restricted to non-commercial and no derivative uses. Users may also download and save a local copy of an article accessed in an institutional repository for the user's personal reference. For permission to reuse an article, please follow our Process for Requesting Permission.

\& Miller, 2016). Mindfulness has also been found to lessen the detrimental impact of real stressors and unavoidable distressing life events on individuals' mental health, thus allowing them to adaptively cope with these stressors (Bergomi et al., 2013). In turn, it is possible that these benefits of mindfulness could lead to increased self-efficacy in the face of past challenges, as they permit individuals to focus on a problem-solving approach to current challenges.

Additionally, since mindfulness has been shown to improve the quality of inter- personal relationships (Carson, Carson, Gil, \& Baucom, 2004), it is possible that individuals who are more mindful also elicit greater support from family and friends. Similarly, it is not surprising that higher levels of dispositional mindful- ness would be associated with better adjustment to university since the link between mindfulness and greater well-being has already clearly been established (e.g., Hanley et al., 2015; Keng, Smoski, \& Robins, 2011).

Although all adjustment subscales were significantly moderately correlated with one another, the social and institutional attachment subscales in particular revealed a high correlation. Social adjustment to university has been proposed to combine both integration into the school community and the creation of support networks, and commitment to a university is related to how individuals integrate socially (Enochs \& Roland, 2006; Gerdes \& Mallinkcrodt, 1994). Universities provide students with many opportunities to become involved in campus life, and thus develop relationships; therefore, when students indicate that they feel socially adjusted within their institution, it is likely that they will feel attached to their institution as well. As expected, although self-efficacy and perceived social support from friends significantly predicted some aspects of adjustment to university, dispositional mindfulness still significantly contributed to university adjustment when control- ling for all other predictors. Interestingly, compared with other aspects of adjustment, dispositional mindfulness was found to most 
strongly contribute to personal or emotional adjustment. This finding is consistent with research conducted by Ramler et al. (2016) which has shown that a mindfulness-based intervention could be effective in fostering adjustment to university among first-year students, especially for the personal or emotional domain of adjustment. The strong contribution of dispositional mindfulness to personal or emotional adjustment could be explained by the relation of both of these factors with well-being since (a) the personal or emotional adjustment scale taps into individuals' psychological well-being, and (b) dispositional mindfulness has been found to contribute to well-being (e.g., Hanley et al., 2015; Keng et al., 2011).

Although perceived social support from family was not a significant predictor of adjustment to university, perceived social support from friends significantly predicted social and institutional attachment, even when controlling for dispositional mindfulness. This finding suggests increased social support from friends may be a stronger predictor of improved social adjustment in first-year students relative to perceived social support from family. Given that students attending university might be living away from home for the first time, it is possible that the perceived support and availability of friends in this new environment is a necessary determinant and resource for adjustment (Friedlander et al., 2007).

However, research by Tinsley Li et al. (2014) suggests that perceived social support from peers partially mediates the relationship between perceived social support from parents and psychological adjustment in a sample of university students. Therefore, additional research is necessary to clarify the complex relationship between perceived social support from friends and family.

Findings obtained in the present study also revealed that when dispositional mindfulness was added to the regression model, self-efficacy and perceived social support from friends were 
Mettler, Dispositional Mindfulness and Adjustment to University, 'Journal of College Student Retention: Research, Theory \& Practice' $(21,1)$ pp. 38-52. Copyright (C) 2017. DOI:

$10.1177 / 1521025116688905$. Users who receive access to an article through a repository are reminded that the article is protected by copyright and reuse is restricted to non-commercial and no derivative uses. Users may also download and save a local copy of an article accessed in an institutional repository for the user's personal reference. For permission to reuse an article, please follow our Process for Requesting Permission.

no longer significant predictors for personal or emotional adjustment. This suggests that some aspects of self-efficacy or perceived social support from friends that predict personal or emotional adjustment may potentially be explained through the influence of dispositional mindfulness. This finding is consistent with previous research by Klainin-Yobas et al. (2016) which demonstrated that mindfulness was the strongest predictor of positive psycho- logical well-being in university students compared with self-efficacy and social support from friends. One of the ways in which mindfulness may influence individuals' self-efficacy is by enhancing the ability to cope in distressing situations (e.g., Bergomi et al., 2013). Furthermore, individuals who report high dispositional mindfulness may also report high perceived social support from friends as mindfulness has been found to enhance communication skills such as empathic perspective taking (Birnie, Speca, \& Carlson, 2010), thus potentially fostering better relationship quality. Finally, being nonjudgmentally aware in the present moment may facilitate individuals' capacity to recognize the support being offered by others. Therefore, dispositional mindfulness can potentially influence individuals' reports of self-efficacy, perceived social support from friends, and promote psychological and emotional well-being. This influential role can help explain why dispositional mindfulness would account for the variance shared by university students' personal or emotional adjustment and reports of self-efficacy or perceived social support from friends in the regression model.

\section{Limitations and Future Directions}

The current study is not without limitations. First, this study was designed to assess data at a single time point, which does not permit for causality to be ascertained. Future research would benefit from a longitudinal design with multiple time points in order to determine whether dispositional mindfulness can predict adjustment over time throughout the first year of university 
when con- trolling for self-efficacy and perceived social support from friends and family.

Second, although the MAAS is a commonly used measure of dispositional mindfulness with strong psychometric properties, using a multidimensional measure of dispositional mindfulness would be helpful to elucidate which aspect of mindfulness has the most impact on adjustment to university. Third, other factors such as financial strain, degree of academic preparation prior to entering university, or being first-generation students are known to have a detrimental impact on university adjustment (e.g., Adams et al., 2016; Martinez et al., 2009) and, given their exacerbating effect on students' perceived stress, could potentially be influenced by mindfulness-based interventions. Specifically, mindfulness may foster students' ability to focus on their studies despite the ongoing stress these difficulties pose. Therefore, given that this was beyond the scope of the current study, further research should investigate the role of dispositional mindfulness in potentially mitigating the impacts of these factors on students' adjustment to university. Finally, data were obtained entirely through self-report measures, and thus may have been subject to response biases. Future research using a mixed method approach would serve to solidify these findings.

\section{Conclusion}

Despite these limitations, the findings obtained in this study provide preliminary empirical support for the incorporation of dispositional mindfulness to resources used by universities to promote successful adjustment to university for incoming students. Although there has been some evidence for the effective- ness of mindfulness interventions to support university adjustment (Ramler et al., 2016), our findings suggest that when controlling for other individual factors, dispositional mindfulness in particular can significantly impact university adjustment. Given that students' wellness is increasingly becoming a priority on university campuses, it 
Mettler, Dispositional Mindfulness and Adjustment to University, 'Journal of College Student Retention: Research, Theory \& Practice' $(21,1)$ pp. 38-52. Copyright (C) 2017. DOI:

$10.1177 / 1521025116688905$. Users who receive access to an article through a repository are reminded that the article is protected by copyright and reuse is restricted to non-commercial and no derivative uses. Users may also download and save a local copy of an article accessed in an institutional repository for the user's personal reference. For permission to reuse an article, please follow our Process for Requesting Permission.

would be important for university mental health and counseling services to provide

psychoeducation on mindfulness and mindful- ness-based training as part of the resources

offered to first-year students in order to better support them as they transition to university. 


\section{References}

Adams, D. R., Meyers, S. A., \& Beidas, R. S. (2016). The relationship between financial strain, perceived stress, psychological symptoms, and academic and social integration in undergraduate students. Journal of American College Health, 64, 362-370. doi:10.1080/07448481.2016.1154559

American College Health Association. (2015). National college health assessment II: Reference group executive summary spring 2015. Hanover, MD: Author.

Baker, R. W., \& Siryk, B. (1999). SACQ student adaptation to college questionnaire (2nd ed.). Los Angeles, CA: Western Psychological Services.

Bamber, M. D., \& Kraenzle Schneider, J. (2016). Mindfulness-based meditation to decrease stress and anxiety in college students: A narrative synthesis of the research. Educational Research Review, 18, 1-32. doi:10.1016/j.edurev.2015.12.004

Bergin, A. J., \& Pakenham, K. I. (2016). The stress-buffering role of mindfulness in the relationship between perceived stress and psychological adjustment. Mindfulness, 7, 928-939. . doi:10.1007/s12671-016-0532-x

Bergomi, C., Stro“hle, G., Michalak, J., Funke, F., \& Berking, M. (2013). Facing the dreaded: Does mindfulness facilitate coping with distressing experiences? A moderator analysis. Cognitive Behaviour Therapy, 42(1), 21-30.

doi:10.1080/16506073.2012.713391

Birnie, K., Speca, M., \& Carlson, L. E. (2010). Exploring self-compassion and empathy in the context of mindfulness-based stress reduction (MBSR). Stress and Health, 26, 359-371. doi:10.1002/smi.1305 
Mettler, Dispositional Mindfulness and Adjustment to University, 'Journal of College Student Retention: Research, Theory \& Practice' $(21,1)$ pp. 38-52. Copyright (C) 2017. DOI:

$10.1177 / 1521025116688905$. Users who receive access to an article through a repository are reminded that the article is protected by copyright and reuse is restricted to non-commercial and no derivative uses. Users may also download and save a local copy of an article accessed in an institutional repository for the user's personal reference. For permission to reuse an article, please follow our Process for Requesting Permission.

Brandy, J. M., Penckofer, S., Solari-Twadell, P. A., \& Velsor-Friedrich, B. (2015). Factors

predictive of depression in first-year college students. Journal of Psychosocial Nursing and Mental Health Services, 53(2), 38.44.

Brown, K. W., \& Ryan, R. M. (2003). The benefits of being present: Mindfulness and its role in psychological well-being. Journal of Personality and Social Psychology, 84(4), 822-848. doi:0.1037/0022-3514.84.4.822

Caldwell, K., Harrison, M., Adams, M., Quin, R. H., \& Greeson, J. (2010). Developing mindfulness in college students through movement-based courses: Effects on self regulatory self-efficacy, mood, stress, and sleep quality. Journal of American College Health, 58(4), 433-442. doi:10.1080/07448480903540481

Carson, J. W., Carson, K. M., Gil, K. M., \& Baucom, D. H. (2004). Mindfulness-based relationship enhancement. Behavior Therapy, 35, 471-494. doi:10.1016/S00057894(04)80028-5

Chao, R. (2012). Managing perceived stress among college students: The roles of social support and dysfunctional coping. Journal of College Counseling, 15(5), 5-22. doi:10.1002/j.2161-1882.2012.00002.

Chemers, M. M., Hu, L., \& Garcia, B. F. (2001). Academic self-efficacy and first year college student performance and adjustment. Journal of Educational Psychology, 93(1), 55-64.

Crede', M., \& Niehorster, S. (2012). Adjustment to college as measured by the student adaptation to college questionnaire: A quantitative review of its structure and relationships with correlates and consequences. Educational Psychology Review, 24, 133-165. doi:10.1007/s10648-011-9184-5

Dyson, R., \& Renk, K. (2006). Freshman adaptation to university life: Depressive symp- toms, 
stress, and coping. Journal of Clinical Psychology, 62(10), 1231-1244.

doi:10.1002/jclp.20295

Enochs, W. K., \& Roland, C. B. (2006). Social adjustment of college freshmen: The importance of gender and living environment. College Student Journal, 40(1), 63-73.

Feldman, G., Lavallee, J., Gildawie, K., \& Greeson, J. M. (2016). Dispositional mind- fulness uncouples physiological and emotional reactivity to a laboratory stressor and emotional reactivity to executive functioning lapses in daily life. Mindfulness, 7, 527-541. doi:10.1007/s12671-015-0487-3

Friedlander, L. J., Reid, G. J., Shupak, N., \& Cribbie, R. (2007). Social support, self-esteem, and stress as predictors of adjustment to university among first-year undergraduates. Journal of College Student Development, 48(3), 259-274. doi:10.1353/csd.2007.0024

Gerdes, H., \& Mallinckrodt, B. (1994). Emotional, social, and academic adjustment of college students: A longitudinal study of retention. Journal of Counselling and Development, 72, $281-288$.

Hanley, A., Warner, A., \& Garland, E. L. (2015). Associations between mindfulness, psychological well-being, and subjective well-being with respect to contemplative practice. Journal of Happiness Studies, 16(6), 1423-1436. doi:10.1007/s10902-014-9569-5

Kabat-Zinn, J. (1994). Wherever you go, there you are. New York, NY: Hyperion.

Kadziolka, M. J., Di Pierdomenico, E. A., \& Miller, C. J. (2016). Trait-like mindfulness promotes healthy self-regulation of stress. Mindfulness, 7(1), 236-245. doi:10.1007/ s12671-015-0437-0

Keng, S.-L., Smoski, M. J., \& Robins, C. J. (2011). Effects of mindfulness on psycho- logical health: A review of empirical studies. Clinical Psychology Review, 31, 1041-1056. 
Mettler, Dispositional Mindfulness and Adjustment to University, 'Journal of College Student Retention: Research, Theory \& Practice' $(21,1)$ pp. 38-52. Copyright (C) 2017. DOI:

$10.1177 / 1521025116688905$. Users who receive access to an article through a repository are reminded that the article is protected by copyright and reuse is restricted to non-commercial and no derivative uses. Users may also download and save a local copy of an article accessed in an institutional repository for the user's personal reference. For permission to reuse an article, please follow our Process for Requesting Permission.

doi:10.1016/j.cpr.2011.04.006

Keng, S.-L., Smoski, M. J., \& Robins, C. J. (2016). Effects of mindful acceptance and reappraisal training on maladaptive beliefs about rumination. Mindfulness, 7, 493-503. doi:10.1007/s12671-015-0480-X

Khoury, B., Lecomte, T., Fortin, G., Masse, M., Therien, P., Bouchard, V., .. . Hofmann, S. G. (2013). Mindfulness-based therapy: A comprehensive meta-analysis. Clinical Psychology Review, 33(6), 763-771. doi:10.1016/j.cpr.2013.05.005

Klainin-Yobas, P., Ramirez, D., Fernandez, Z., Sarmiento, J., Thanoi, W., Ignacio, J., \& Lau, Y. (2016). Examining the predicting effect of mindfulness on psychological well- being among undergraduate students: A structural equation modeling approach. Personality and Individual Differences, 91, 63-68.

Krumrei-Mancuso, E. J., Newton, F. B., Kim, E., \& Wilcox, D. (2013). Psychosocial factors predicting first-year college student success. Journal of College Student Development, 54(3), 247-266. doi:10.1353/csd.2013.0034

Lee, C., Dickson, D. A., Conley, C. S., \& Holmbeck, G. N. (2014). A closer look at self- esteem, perceived social support, and coping strategy: a prospective study of depres- sive symptomatology across the transition to college. Journal of Social and Clinical Psychology, 33(6), 560-585. doi:10.1521/jscp.2014.33.6.560

Marks, A. D. G., Sobanski, D. J., \& Hine, D. W. (2010). Do dispositional rumination and/ or mindfulness moderate the relationship between life hassles and psychological dysfunction in adolescents? Australian and New Zealand Journal of Psychiatry, 44(9), $831-838$.

Martinez, J. A., Sher, K. J., Krull, J. L., \& Wood, P. K. (2009). Blue-collar scholars?: Mediators 
and moderators of university attrition in first-generation college students. Journal of College Student Development, 50(1), 87-103. doi:10.1353/csd.0.0053

Palmer, A., \& Rodger, S. (2009). Mindfulness, stress, and coping among university stu- dents. Canadian Journal of Counselling, 43(3), 198-212.

Parker, S. C., Nelson, B. W., Epel, E. S., \& Siegel, D. J. (2015). The science of presence: A central mediator of the interpersonal benefits of mindfulness. In K. W. Brown, J.

D. Creswell \& R. M. Ryan (Eds.), Handbook of mindfulness: Theory, research and practice (pp. 225-244). New York, NY: The Guilford Press.

Ramler, T. R., Tennison, L. R., Lynch, J., \& Murphy, P. (2016). Mindfulness and the college transition: The efficacy of an adapted mindfulness-based stress reduction inter- vention in fostering adjustment among first-year university students. Mindfulness, 7, 179-188. doi:10.1007/s12671-015-0398-3

Ramos-Sanchez, L., \& Nichols, L. (2007). Self-efficacy of first- generation and non-firstgeneration college students: The relationship with academic performance and college adjustment. Journal of College Counselling, 10, 6-18. doi:10.1002/j.21611882.2007.tb00002.x

Schwarzer, R., \& Jerusalem, M. (1995). Generalized self-efficacy scale. In J. Weinman, S. Wright \& M. Johnston (Eds.), Measures in health psychology: A user's portfolio. Causal and control beliefs (pp. 35-37). Windsor, England: NFER-Nelson.

Shapiro, S. L., Brown, K. W., Thoresen, C., \& Plante, T. G. (2011). The moderation of mindfulness-based stress reduction effects by trait mindfulness: Results from a randomized controlled trial. Journal of Clinical Psychology, 67(3), 267-277. doi:10.1002/jclp.20761 
Mettler, Dispositional Mindfulness and Adjustment to University, 'Journal of College Student Retention: Research, Theory \& Practice' $(21,1)$ pp. 38-52. Copyright (C) 2017. DOI:

$10.1177 / 1521025116688905$. Users who receive access to an article through a repository are reminded that the article is protected by copyright and reuse is restricted to non-commercial and no derivative uses. Users may also download and save a local copy of an article accessed in an institutional repository for the user's personal reference. For permission to reuse an article, please follow our Process for Requesting Permission.

Tao, S., Dong, Q., Pratt, M., Hunsberger, B., \& Pancer, S. (2000). Social support: Relations to coping and adjustment during the transition to university in the people's republic of China. Journal of Adolescent Research, 15(1), 123-144. doi:10.1177/ 0743558400151007

Tinsley Li, S., Berman Albert, A., \& Dwelle, D. G. (2014). Parental and peer support as predictors of depression and self-esteem among college students. Journal of College Student Development, 55(2), 120-138. doi:10.1353/csd.2014.0015

Zimet, G. D., Dahlem, N. W., Zimet, S. G., \& Farley, G. K. (1988). The multidimensional scale of perceived social support. Journal of Personality Assessment, 52(1), 30-41. doi:10.1207/s15327752jpa5201_2. 


\section{Tables and Figures}

Table 1. Correlations Between Study Variables.

\begin{tabular}{|c|c|c|c|c|c|c|c|c|}
\hline & 1 & 2 & 3 & 4 & 5 & 6 & 7 & 8 \\
\hline \multicolumn{9}{|c|}{ 1. Gender } \\
\hline \multicolumn{9}{|c|}{ 2. Mindfulness } \\
\hline$r$ & .05 & 1 & & & & & & \\
\hline$n$ & 88 & & & & & & & \\
\hline \multicolumn{9}{|c|}{ 3.General self-efficacy } \\
\hline$r$ & -.08 & $.35^{\star *}$ & 1 & & & & & \\
\hline$n$ & 88 & 88 & & & & & & \\
\hline \multicolumn{9}{|c|}{ 4. Support from family } \\
\hline$n$ & 88 & 88 & 88 & & & & & \\
\hline \multicolumn{9}{|c|}{ 5. Support from friends } \\
\hline$r$ & .08 & $.37^{\star *}$ & .18 & $.40^{\star *}$ & 1 & & & \\
\hline$n$ & 88 & 88 & 88 & 88 & & & & \\
\hline \multicolumn{9}{|c|}{ 6. Academic adjustment } \\
\hline$r$ & -.05 & $.43^{* *}$ & $.34^{* *}$ & .26 & .26 & 1 & & \\
\hline$n$ & 87 & 87 & 87 & 87 & 87 & & & \\
\hline
\end{tabular}

7. Social adjustment

$\begin{array}{llllllll}r & .23 & .5^{\star *} & .33^{*} & .26 & .54^{\star *} & .47^{\star *} & 1 \\ n & 87 & 87 & 87 & 87 & 87 & 87 & \end{array}$

8. Personal and emotional adjustment

$\begin{array}{lllllllll}r & .03 & .61^{* *} & .36^{* *} & .25 & .37^{* *} & .51^{* *} & .44^{* *} & 1 \\ n & 87 & 87 & 87 & 87 & 87 & 87 & 87 & \end{array}$

9. Attachment adjustment

$\begin{array}{llllllllll}r & .22 & .47^{\star *} & .17 & .26 & .46^{* *} & .58^{\star *} & .85^{\star *} & .44^{\star *} & 1 \\ n & 87 & 87 & 87 & 87 & 87 & 87 & 87 & 87\end{array}$

Note. Given the multiple comparisons being made, the Bonferroni correction was used to obtain an alpha level of .002 to test for significance.

${ }^{*} p<.002 .{ }^{* *} p<.001$.

Table 2. Means and Standard Deviations for All Predictor and Outcome Variables $(n=\underline{87})$

\begin{tabular}{lrr} 
& \multicolumn{1}{c}{ M } & SD \\
\hline Self-efficacy & 30.67 & 4.22 \\
Support from family & 20.62 & 5.65 \\
Support from friends & 20.53 & 5.27 \\
Mindfulness & 54.84 & 12.97 \\
Academic adjustment & 130.60 & 25.20 \\
Social adjustment & 104.15 & 27.52 \\
Personal or emotional adjustment & 77.51 & 21.19 \\
Institutional attachment adjustment & 95.00 & 20.18 \\
\hline
\end{tabular}


Mettler, Dispositional Mindfulness and Adjustment to University, 'Journal of College Student Retention: Research, Theory \& Practice' $(21,1)$ pp. 38-52. Copyright (C) 2017. DOI:

$10.1177 / 1521025116688905$. Users who receive access to an article through a repository are reminded that the article is protected by copyright and reuse is restricted to non-commercial and no derivative uses. Users may also download and save a local copy of an article accessed in an institutional repository for the user's personal reference. For permission to reuse an article, please follow our Process for Requesting Permission.

\begin{tabular}{|c|c|c|c|c|c|c|c|c|c|c|c|}
\hline & \multicolumn{3}{|c|}{$\begin{array}{l}\text { Regression } \\
\text { for academic } \\
\text { adjustment }\end{array}$} & \multicolumn{3}{|c|}{$\begin{array}{l}\text { Regression } \\
\text { for social } \\
\text { adjustment }\end{array}$} & \multicolumn{3}{|c|}{$\begin{array}{l}\text { Regression for } \\
\text { personal or } \\
\text { emotional } \\
\text { adjustment }\end{array}$} & \multicolumn{2}{|c|}{$\begin{array}{c}\text { Regression for } \\
\text { institutional } \\
\text { attachment } \\
\text { adjustment }\end{array}$} \\
\hline & B & SE B & $\beta$ & B & SE B & $\beta$ & B & SE B & $\beta$ & $B$ & SE B \\
\hline \multicolumn{12}{|l|}{ Step I } \\
\hline Constant & 44.3 & 20.35 & & -2.81 & 19.78 & & -1.33 & 16.56 & & 41.42 & 15.90 \\
\hline Self-efficacy & 1.82 & 0.60 & $.30 * *$ & 1.62 & 0.58 & $.25 * *$ & 1.54 & 0.49 & $31 * *$ & 0.47 & 0.47 .10 \\
\hline Support from family & 0.78 & 0.48 & & 0.27 & 0.477 & .06 & 0.45 & 0.39 . & 12 & 0.37 & 0.37 .10 \\
\hline Support from friends & 0.71 & 0.52 & & 2.51 & 0.50 & $.48 * * *$ & 1.10 & 0.42 . & $27 *$ & 1.53 & $0.40 .40 * * *$ \\
\hline \multicolumn{12}{|c|}{ Step 2} \\
\hline Constant & 40.31 & 19.70 & & -7.23 & 18.90 & & -7.08 & 14.48 & & 37.59 & 15.06 \\
\hline Self-efficacy & 1.34 & 0.61 & $.23^{*}$ & 1.10 & 0.58 & .17 & 0.86 & 0.45 & & 0.02 & 0.46 .004 \\
\hline Support from family & 0.49 & 0.48 & & -0.06 & 0.46 & -.01 & 0.02 & 0.35 . & 004 & 0.08 & 0.36 .02 \\
\hline Support from friends & 0.39 & 0.51 & & 2.16 & 0.49 & $.4 I^{* * *}$ & 0.64 & 0.38 . & 16 & 1.23 & $0.39 .32 * *$ \\
\hline Mindfulness & 0.57 & 0.21 & $.29 * *$ & 0.63 & 0.21 & $.30 * *$ & 0.82 & 0.16 & $50 * * *$ & 0.55 & $0.16 .35^{* * * *}$ \\
\hline
\end{tabular}

Table 3. Summary of Hierarchical Multiple Regression Analyses for Each Domain of Adjustment to University. 